Article

\title{
Acoustic Emission Based on Cluster and Sentry Function to Monitor Tensile Progressive Damage of Carbon Fiber Woven Composites
}

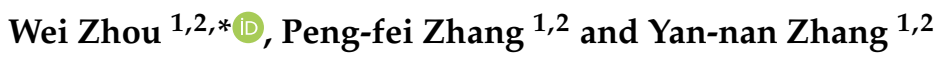 \\ 1 College of Quality and Technical Supervision, Hebei University, Baoding 071002, China; \\ fei960604@126.com (P.-f.Z.); zhangyannanhbu@163.com (Y.-n.Z.) \\ 2 Non-Destructive Testing Laboratory, Hebei University, Baoding 071002, China \\ * Correspondence: zhouweihy@126.com or zhouwei@hbu.edu.cn
}

Received: 24 October 2018; Accepted: 13 November 2018; Published: 16 November 2018

check for updates

\begin{abstract}
Understanding the tensile failure mechanisms in carbon fiber woven composites based on the acoustic emission (AE) technique is a challenging task. In this study, the mechanical behaviors of composites were studied under uniaxial tensile loading. Meanwhile, the internal damage evolution process in composites was monitored by $\mathrm{AE}$ and the recorded $\mathrm{AE}$ signals were analyzed. To achieve the dominant damage mechanisms in composites, five $\mathrm{AE}$ parameters such as rise time, duration, energy, peak amplitude, and frequency were selected for cluster analysis by a k-means algorithm. The results show that $\mathrm{AE}$ signals can be divided into three clusters based on microscopic observations and frequency range. The three clusters correspond to three kinds of damage modes such as matrix cracking, fiber/matrix debonding, and fiber breakage. In addition, the sentry function (SF) was adopted to investigate $\mathrm{AE}$ signals originated from the internal damage evolution in composites. It was found that the drop in the SF curve corresponds to the serious damage of the composites.
\end{abstract}

Keywords: carbon fiber woven composites; cluster analysis; damage mechanism; AE; Sentry Function

\section{Introduction}

Carbon fiber woven composites have been used in a wide range of applications in, for example, aerospace, automobile, and industry due to their high specific strength and stiffness and other outstanding properties [1-4]. However, in spite of these advantages, damages such as matrix cracking and debonding that appear during the manufacturing and service processes are still unavoidable. Therefore, characterization and process monitoring of the damage evolution of the composites is highly necessary [5-9]. Up to now, some methods such as impedance spectroscopy [10], eddy current testing [11], and the residual strength technique [12] have been used to monitor the progressive damage in materials. By contrast, acoustic emission (AE) technology can provide real-time information varying with external variables such as load, time, and temperature. Therefore, it has been used more and more widely in online monitoring and the early prediction of damage [13-15].

The AE technique is based on the principle of the rapid release of elastic waves induced by local damage sources in composites and has been widely applied for structural health monitoring and damage evaluation of the composites in real time [16-18]. According to the AE signal waveform collected by sensors, some characteristic parameters like peak amplitude, energy, and duration can be obtained, which provides an indication about the damage evolution of the composites during the tensile and compressive tests $[19,20]$. Silversides et al. [21] proposed an experimental methodology based on $\mathrm{AE}$ wave detection for determining delamination onset and propagation in carbon fiber composite materials under quasi-static and fatigue loading. It was found that $\mathrm{AE}$ energy distributions 
are well correlated with the delamination length and the crack growth rate. Karahan et al. [22] reported a significant correlation between the damage mechanism and textile architecture of $2 \times 2$ twill carbon-epoxy composites. It was found that the fiber volume fraction has barely affected characteristic strain values while the first $\mathrm{AE}$ event is recorded. In addition, the $\mathrm{AE}$ technique can also evaluate the different failure mechanisms of the composites [23-25]. Woo et al. [26] studied the failure characteristics of carbon/Kevlar hybrid composites by using the $\mathrm{AE}$ technique under high strain-rate compressive loading. The results showed that AE signals can reflect the dynamic behaviors and failure modes in composites. The amplitude range of matrix cracking, fiber-matrix debonding, and fiber breakage is from 42 to 43 , from 50 to 65 , and over $94 \mathrm{~dB}$, respectively.

Up to now, investigation on the mechanical testing, nondestructive testing (NDT), and failure behaviors of the composites on the tensile condition have been carried out by some researchers [27]. Ryu et al. [28] conducted the tensile mechanical properties and fracture characteristics of carbon fiber reinforced plastic (CFRP) composites embedded with $\mathrm{SiC}$ powder by using the $\mathrm{AE}$ technique. It was found that the fracture behavior of the SiC reinforced CFRP composites could be effectively evaluated on the basis of the specific AE frequency bands. Li et al. [29] used the shear-lag model to describe the micro stress field of the damaged composites for determining the microdamage parameters. It can be found that the occurrence of multiple damage mechanisms, i.e., matrix cracking, fiber/matrix interface debonding, and fiber breakage, is the main reason for the non-linear characteristic of the composites.

In the case of the analysis of AE signals, Li et al. [30] reported a result that the cluster identification creates a link between damage mode and $\mathrm{AE}$ parameters of the corresponding $\mathrm{AE}$ events by cluster analysis which was based on the k-means++ algorithm and principal component analysis (PCA) of $\mathrm{AE}$ signals for woven glass/epoxy composites. It was found that cluster analysis is an effective method to analyze AE signals. Furthermore, in the judgment of the damage state, the sentry function (SF), which has been used to specify the behavior of composites under tensile test [31], is used an aided validation method to describe the damage in composites. Zhou et al. [32] used AE technology to monitor the buckling process of multi-delaminated composites and analyzed AE signals based on the k-means algorithm and PCA. The results showed that AE signals of the compression process can be divided into three clusters, which represent three kinds of damage modes such as matrix cracking, fiber/matrix debonding, delamination and fiber breakage, respectively.

In this study, mechanical characterization and failure processes of carbon fiber woven composites were conducted under a tensile loading condition. For a better understanding of the damage and evolution of the composites, $\mathrm{AE}$ characteristic parameters such as $\mathrm{AE}$ count, energy, and peak amplitude and frequency were used to analyze the damage behavior in composites. This paper addresses a new method based on the mechanical behavior and AE information. Compared with other literature, this method not only uses the k-means algorithm cluster analysis to identify the tensile progressive damage and failure mechanism but also combines the peak frequency distribution with the SF of composite materials during tensile load. This method can determine the behavior and mechanism of the material in different damage stages.

\section{Experimental Procedure}

\subsection{Materials and Specimens}

Carbon fiber woven composites were prepared with six layers of $3 \mathrm{~K}$ carbon fiber orthogonal woven fabric and manufactured by vacuum-assisted resin infusion (VARI) method. Table 1 presents the mechanical and physical properties of the used fibers. The mass ratio of the epoxy resin and the curing agent is 100:34. The as-prepared composite laminates were cured at room temperature for $24 \mathrm{~h}$ and then maintained at $100^{\circ} \mathrm{C}$ for $8 \mathrm{~h}$. Figure la shows a schematic illustration of the weave composite. Finally, the as-prepared composite laminates with a thickness of $1.4 \mathrm{~mm}$ were cut into rectangles with a size of $180 \mathrm{~mm} \times 25 \mathrm{~mm}$. The gauge section of the specimen was $100 \mathrm{~mm}$. Furthermore, two pieces of aluminum plates with the same width of $25 \mathrm{~mm}$ were glued on both ends of the composite specimens 
to prevent any damage from the clamps. A total of five composite specimens were employed, as shown in Figure $1 b$.

Table 1. Mechanical and physical properties of the used carbon fiber.

\begin{tabular}{cc}
\hline Property & Value \\
\hline Tensile strength $(\mathrm{MPa})$ & 2550 \\
Tensile modulus $(\mathrm{GPa})$ & 135 \\
Elongation $(\%)$ & 2.1 \\
Density $\left(\mathrm{g} / \mathrm{cm}^{3}\right)$ & 1.8 \\
\hline
\end{tabular}

(a)

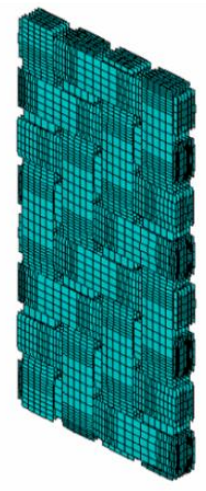

(b)

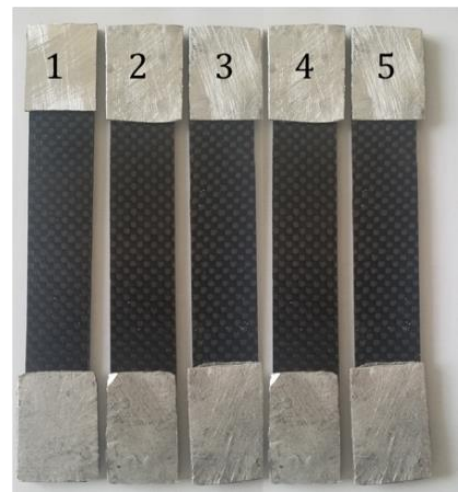

Figure 1. (a) The schematic illustration of weave composite. (b) Images of composite specimens.

\subsection{Experimental Procedures}

The tensile tests of carbon fiber woven composite specimens were carried out with a speed of $1 \mathrm{~mm} / \mathrm{min}$ by an electronic universal testing machine (CMT5305). Real-time AE signals originating from the damage and evolution of the composites were monitored by using a DS2-8A system under tensile loading conditions, as shown in Figure 2. Two RS-54A broadband sensors with the frequency range $100-900 \mathrm{kHz}$ were mounted on the surface of the specimen with a tape and the distance between them was $55 \mathrm{~mm}$. In order to provide a good acoustic coupling, silicone grease was used as a coupling agent between the sensor and the surface of specimen. The sampling frequency was set at $3.5 \mathrm{MHz}$. At the start of the tensile test, a pencil lead break test was performed to verify the transducer coupling. Two sensors verify the correctness of AE signals with each other. One sensor with more signals was selected as the source of the analysis data. The morphology of the fractured composite specimen was observed using scanning electron microscopy (SEM, JEOL JSM-7500F).

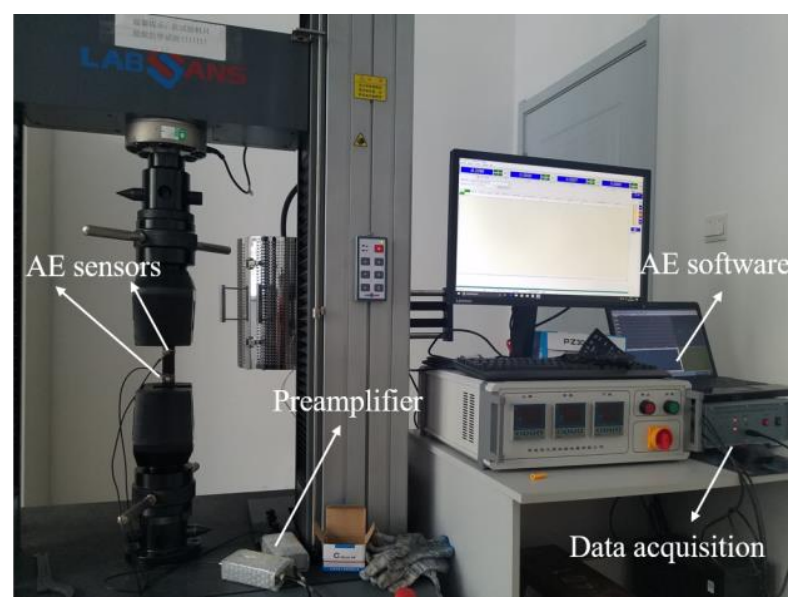

Figure 2. Experimental system of tensile tests and acoustic emission (AE) monitoring. 


\subsection{AE Signal Analysis}

AE sensors were mounted on the surface of the composite specimens, and the recorded AE signals were associated with the damage sources in the composites. Hence, AE parameters can be used to assess the damage behavior of the composites. Figure 3 shows a typical wave shape of a burst-type AE signal. With respect to the damage evaluation, different $\mathrm{AE}$ characteristic parameters reveal different physical significance. The cumulative AE hits are strongly associated with the diversity of signals in composites. The peak amplitude, rise time, duration, and frequency relate to the damage mode (e.g., matrix cracking, delamination, and fiber damage).

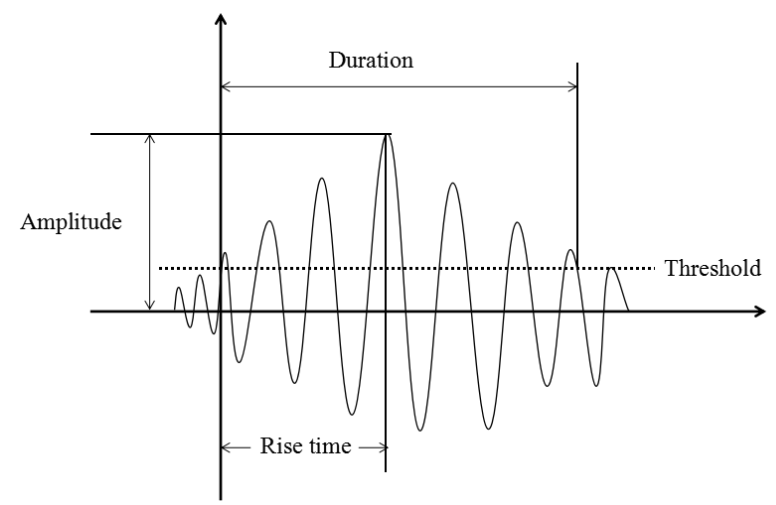

Figure 3. A typical waveform for a burst-type AE signal.

In addition, AE energy can be adopted to describe acoustic activity and fulfill the unsupervised pattern recognition based on the SF. This function is based on the idea that the specimens store strain energy during the loading process and simultaneously release part of the stored energy due to internal damage and focuses on a global variable between $\mathrm{AE}$ activity and the mechanical behavior of composites, which is defined by:

$$
f(x)=\operatorname{Ln}\left[\frac{E_{s}(x)}{E_{a}(x)}\right]
$$

Here, $x, E_{S}(x)$, and $E_{a}(x)$ are the displacement, the strain energy, and the AE events energy, respectively.

On the basis of the previous studies [33-35], this function, $f$, can be defined by five different behaviors, as shown in Figure 4. $\mathrm{S}_{1}$ is related to an increasing trend of the strain energy storing and $S_{2}$ represents the sudden drop of $f$ that indicates the emergence of internal damage in materials. $\mathrm{S}_{3}$ indicates the constant behavior of $f$, which corresponds to an equivalent energy release due to material damage progression. The subsequent Bottom-Up (BU) trend indicates that a strengthening event induced a new energy storing capability in the materials. $S_{4}$ represents the decreasing behavior of $f$, which indicates that the damage has reached a maximum and the material has no resources to sustain the load.

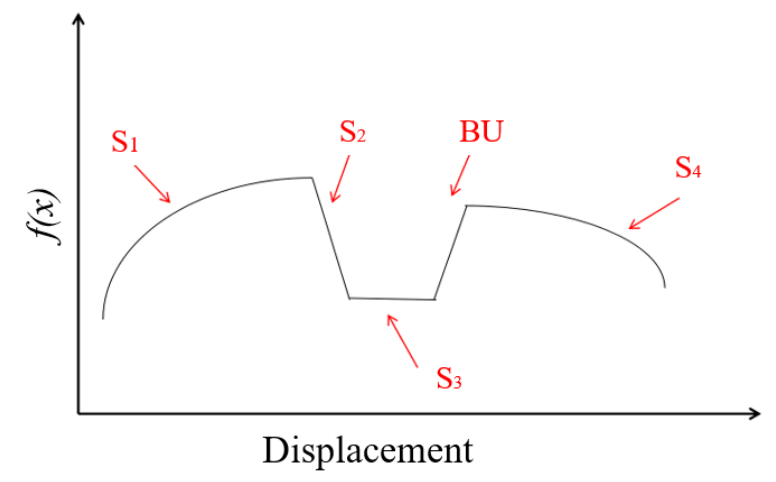

Figure 4. Five different behaviors of sentry function (SF) vs. displacement. 


\section{Results and Discussions}

\subsection{AE Data Filtering and Selecting}

During the real-time AE monitoring, the real AE signals, grip noises, electromagnetic noises, and friction noises will be generally recorded. The lack of an accurate selection of AE signals results in the unavailability of subsequent AE data analysis. Therefore, several methods like high-pass filters and linear source location filters have been proposed to remove the noise and acquire the accurate selection of AE signals originating from the damage [36-38].

Maillet et al. [39] proposed an energy-based approach by using two sensors, which can effectively obtain the accurate location and selection of AE signals originating from the damage of the composites. In order to ensure that most $\mathrm{AE}$ signals were generated in the gauge section, the AE signals were monitored with two identical sensors located $55 \mathrm{~mm}$ apart. From the times of arrival at the top $\left(\mathrm{t}_{1}\right)$ and bottom $\left(t_{2}\right)$ sensors, the time difference is $\Delta t\left(<\Delta t_{\max }\right)$. It could be concluded that most of the AE signals were generated in the gauge section during the tensile process. In addition, Babu et al. [40] concluded that there is a good correlation between the amplitude and duration of AE signals. Similarly, Chai et al. [41] and Yu et al. [42] used amplitude-duration filtering to remove outliers from the AE signals. Therefore, a statistical pattern recognition technique of the Maxmin Distance algorithm was employed to locate outliers [43]. The Maxmin Distance algorithm is a tentative-based algorithm in the field of pattern recognition. The purpose is to select objects that are located far apart from each other as the clustering center, thus avoiding the situation that the clustering seeds are too close when the initial value of the k-means algorithm is selected. The typical AE waveforms are shown in Figure 5a. The high amplitude and low duration (in the range of $0.00008 \mathrm{~s}$ ) waveform at the top of Figure $5 \mathrm{a}$ corresponds to AE events (points) on the bottom right side of Figure 5b. The low-amplitude (near the threshold) and high duration (reaches up to $0.0003 \mathrm{~s}$ ) waveform at the bottom of Figure 5a corresponds to AE events (points) on the upper left side of the Figure $5 \mathrm{~b}$.
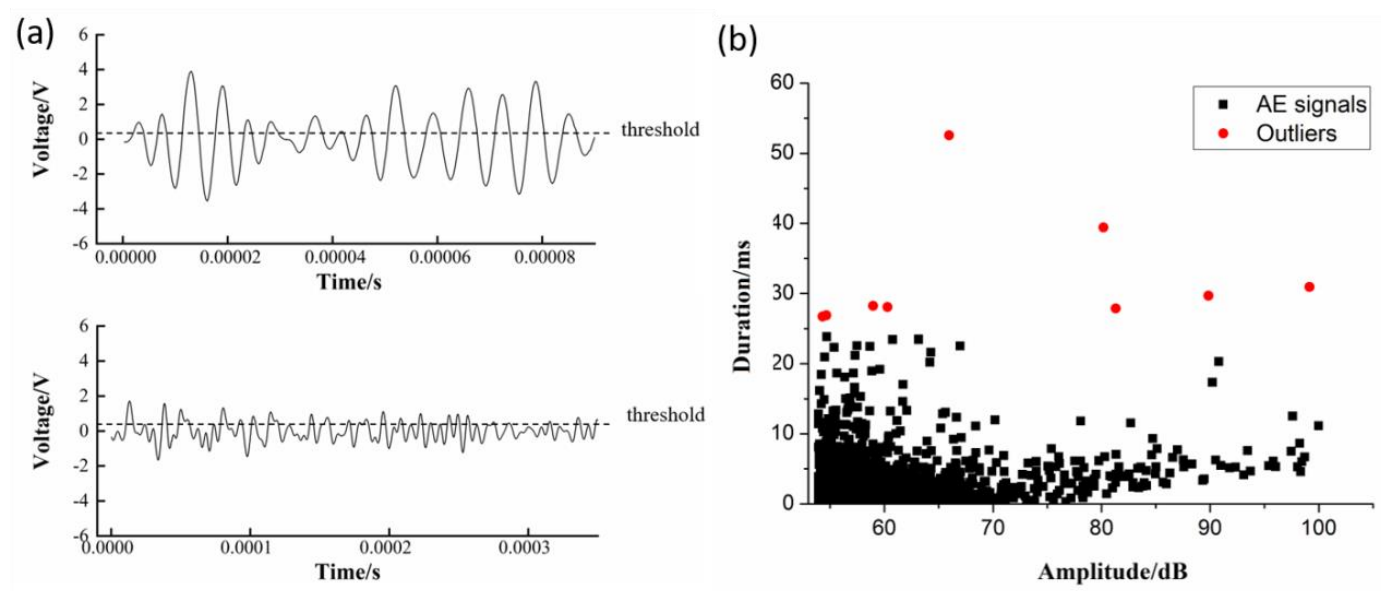

Figure 5. (a) Typical AE waveforms. (b) The relationship between amplitude and duration of the AE signals.

\subsection{Mechanical Behavior}

Five effective tensile tests were conducted to obtain the reproducibility of the experimental results and the corresponding load versus displacement curves are shown in Figure 6. From Figure 6, a nonlinear bend of the curves is observed at low tensile load levels, which may be related to matrix plasticity and cracking [44]. With the tensile load increasing, composite specimens exhibit quasi-brittle linear behavior until their ultimate failure. The average tensile failure load and standard deviation are $19.54 \mathrm{kN}$ and $0.34 \mathrm{kN}$, respectively. Table 2 lists the specific mechanical properties and the AE data. Comparing the test results of the five specimens, it is found that the AE parameters like count, 
amplitude, and frequency of the five specimens are in agreement. Therefore, one typical specimen was chosen to analyze the damage mechanism and $\mathrm{AE}$ response for the composites.

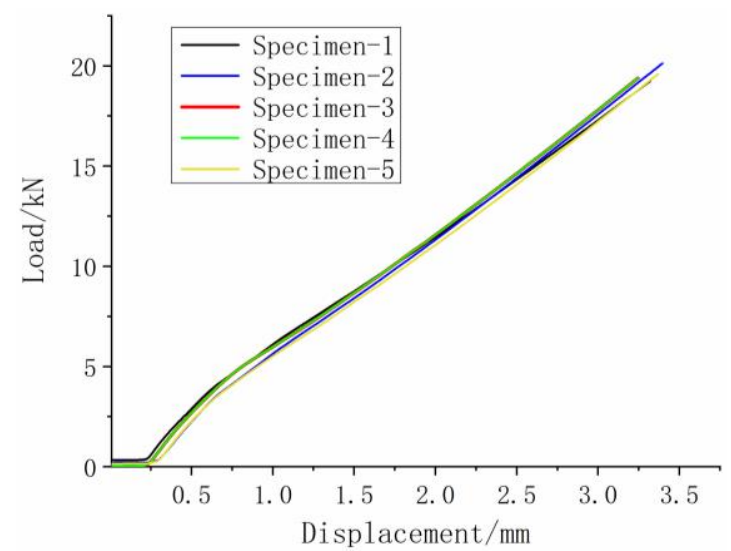

Figure 6. The tensile loading curve versus displacement for the composite specimen.

Table 2. Summary of measured mechanical properties and corresponding AE characteristics.

\begin{tabular}{ccccccc}
\hline \multirow{2}{*}{ Material } & \multicolumn{3}{c}{ Failure Load } & \multicolumn{3}{c}{ AE Parameters } \\
\cline { 2 - 7 } & $\begin{array}{c}\text { Actual } \\
\text { Load (kN) }\end{array}$ & $\begin{array}{c}\text { Mean Value } \\
\mathbf{( k N )}\end{array}$ & $\begin{array}{c}\text { Standard } \\
\text { Deviation }\end{array}$ & AE Count & $\begin{array}{c}\text { Average } \\
\text { Amplitude (dB) }\end{array}$ & $\begin{array}{c}\text { Average } \\
\text { Frequency (kHz) }\end{array}$ \\
\hline Speciment-1 & 19.23 & & & 2489 & 59.09 & 193.60 \\
Speciment-2 & 20.12 & 19.54 & 0.34 & 2791 & 59.15 & 203.17 \\
Speciment-3 & 19.40 & & & 2791 & 64.32 & 175.89 \\
\hline Speciment-4 & 19.39 & & & 2130 & 71.54 & 177.03 \\
Speciment-5 & 19.59 & & & 3140 & 69.79 & 178.14 \\
\hline
\end{tabular}

In order to describe the inner damage of the specimen, the fractured areas were observed with the help of SEM. Figure 7 shows the morphology of the fractured specimen. The image of the whole fractured specimen is shown in Figure 7a, which clearly demonstrates that the specimen is completely broken into two pieces. From Figure $7 \mathrm{~b}$, a large number of delaminations were observed and the obvious matrix crack can be seen. It can be attributed to the inter-laminar separation resulting from the shear stress transfer [45]. From Figure 7c, fiber pull-out and fiber damage can be clearly observed and fiber breakage appears as a brittle fracture. In addition, it is found that the mixed failure mode sustains the balance in the composite specimen.

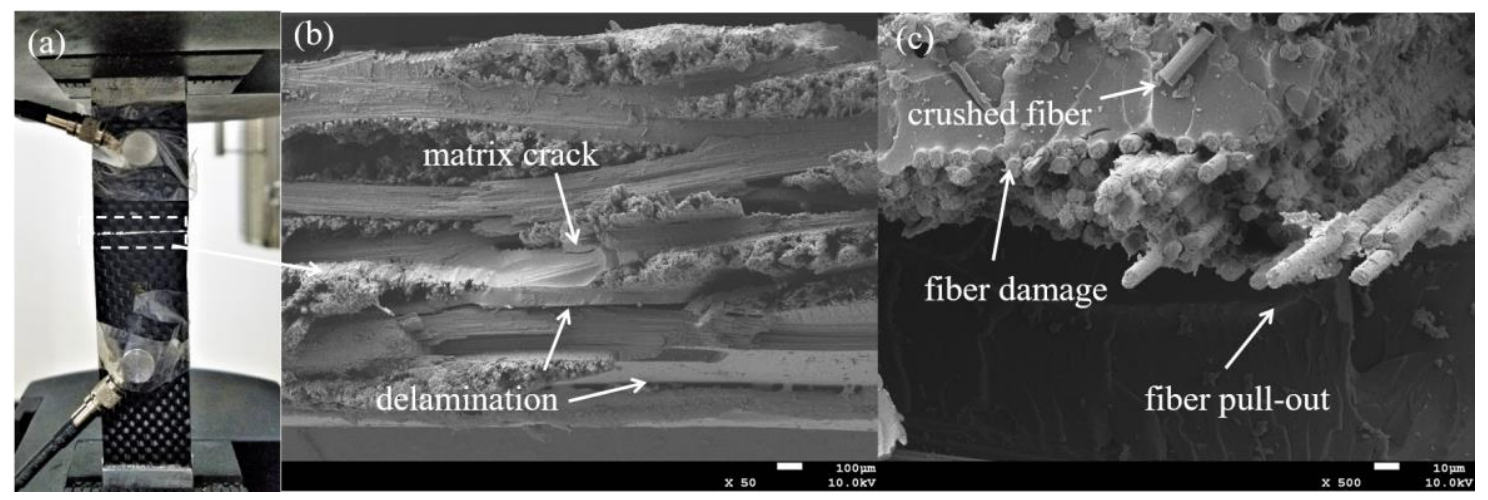

Figure 7. (a) The image of the whole fractured sample. (b,c) SEM micro-photographs of the fractured composite: delamination and matrix crack; fiber breakage and fiber pull out. 


\subsection{AE Behavior under Tensile Tests}

To elucidate the evolution of damage in the composite under a tensile test, the AE parameters such as energy, counts, $\mathrm{AE}$ energy release rate, and $\mathrm{AE}$ hit rate are selected and tensile load, accumulative energy, counts, energy release rate, and $\mathrm{AE}$ event count rate vs. time for the composite specimen are shown in Figure 8. Generally, the variations of accumulative AE energy and AE counts in terms of the slope and the number of hits are associated with internal damage activity and the damage mechanism, respectively. The value of the accumulative $\mathrm{AE}$ count is continuously increasing in progressive damage and there are two inflection points on the AE counts curve. At the first inflection point, AE energy increases sharply and the energy release rate and AE counts are also relatively high, which is attributed to microdamage and matrix cracking in composites. Then, AE energy remains at a high level and AE counts increase gradually, observations that are related to the propagation of microdamage and interfacial failure. Upon reaching the second inflection point, AE energy increases and AE counts and count rate increase sharply. It can be concluded that the fiber/matrix debonding and more serious damage are induced in the composites.

The AE energy release rate, AE hit rate, and their average value can achieve noise discrimination and signal recognition. Three points exist with a high release rate with regard to AE energy and count, suggesting the occurrence of damage in the composite specimen. It is not enough to identify the damage mode in the composite due to the simplicity of the description of the progressive damage profile by AE energy and counting alone. Several studies have successfully established a connection between AE parameters (i.e., amplitude and frequency) and various damage modes of the composites. Babu et al. [40] investigated the distributions of AE signals in amplitude and found that matrix cracking and fiber breakage correspond to 58-65 dB and 89-92 dB, respectively. Gutkin et al. [46] studied the failure mechanism of CFRP under tensile tests and concluded that the frequency band of four failure modes such as matrix cracking, delamination, fiber/matrix deboning, and fiber damage is $0-50 \mathrm{kHz}$, $50-150 \mathrm{kHz}, 200-300 \mathrm{kHz}$, and $400-500 \mathrm{kHz}$, respectively. In this step, these two AE parameters related to various damage modes in composites were compared and the optimal AE parameters were selected to facilitate the identification of damage patterns.
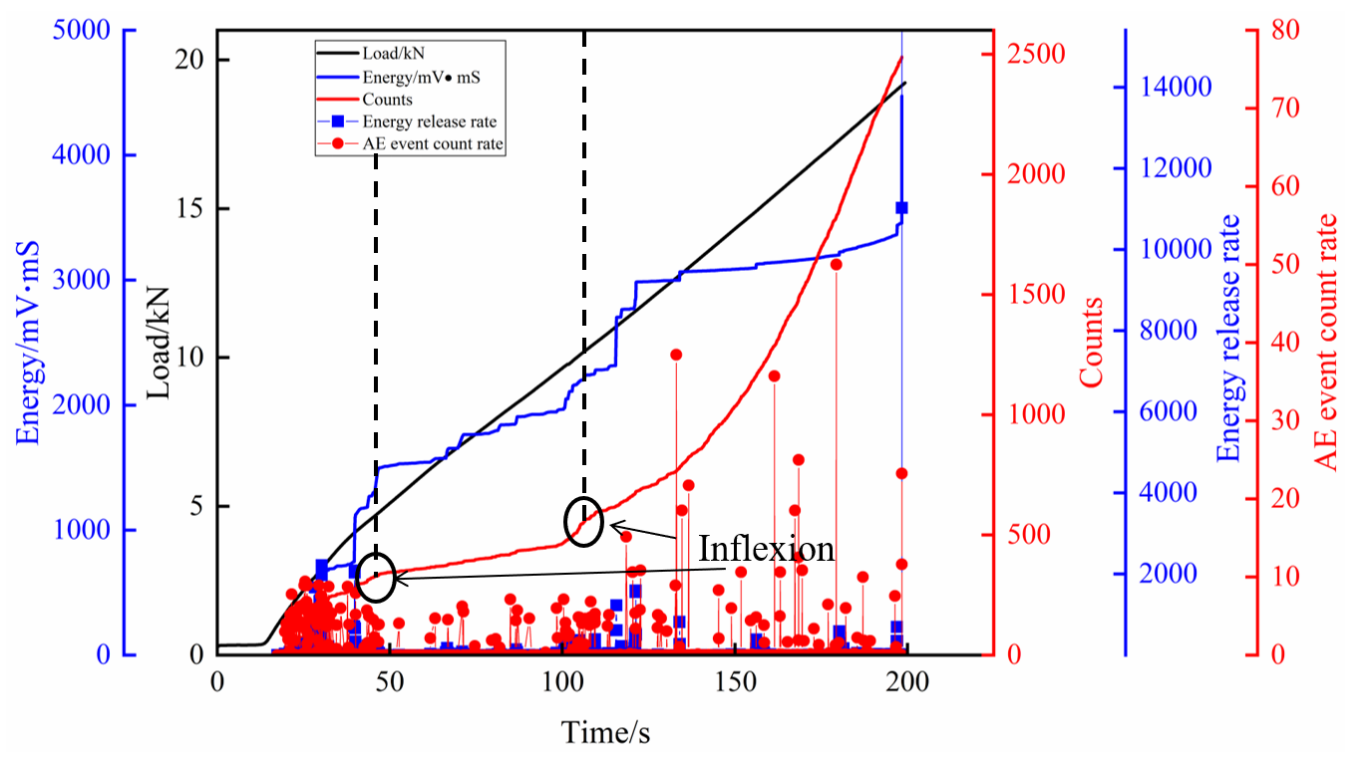

Figure 8. Tensile load, accumulative energy, counts, energy release rate, and AE event count rate vs. time for the composite specimen.

The distinction of AE data with regards to different types of damage mainly reflects different amplitude and peak frequency distribution. By analyzing the distribution characteristics of amplitude and peak frequency, different damage modes can be distinguished and the progressive damage of 
composites can be described. The distribution of the AE amplitude and peak frequency at $30 \%, 60 \%$, and $90 \%$ of the failure load is shown in Figure 9. The dominant amplitude is concentrated in the range of 55 to $65 \mathrm{~dB}$ and this distribution under the evolutionary processes of the tensile damage is nearly consistent, as shown in Figure 9a. Furthermore, the peak frequency distribution of AE signals at different load levels is shown in Figure 9b, the mean value of frequency intervals is $50 \mathrm{kHz}$. There is no dominant $\mathrm{AE}$ event at $30 \%$ of the failure load. Outside the operation frequency range $(100-900 \mathrm{kHz})$, the spectral sensitivities of the sensors drop dramatically. The frequencies below $50 \mathrm{kHz}$ at $60 \%$ of the failure load do not appear to correspond to a specific damage mechanism. As the tensile load increases up to a value that is $90 \%$ of the failure load, the main frequencies range from 200 to $300 \mathrm{kHz}$. More importantly, when the load reaches the failure load, AE signals with high peak frequency over $300 \mathrm{kHz}$ are generated, indicating severe damage in the composites. Hence, compared with the amplitude, the variation with regard to the peak frequency efficaciously described the change in damage mode with progressive failure and the analysis of the mechanism can be conducted based on the K-means method.

(a)

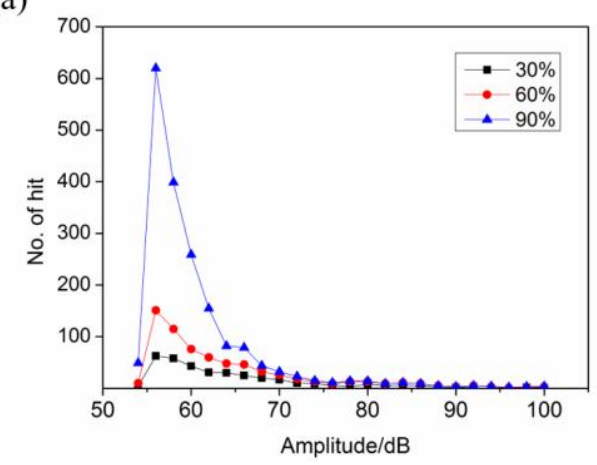

(b)

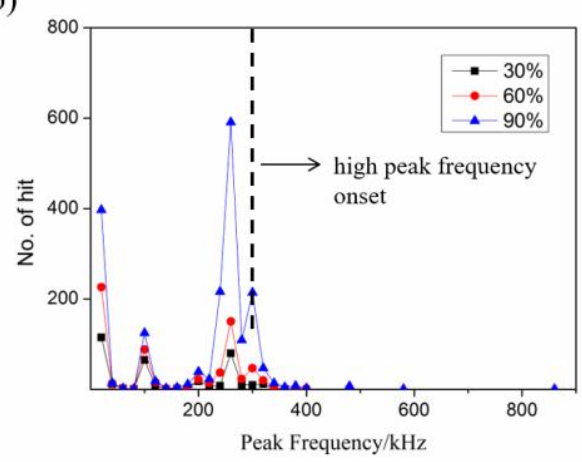

Figure 9. Progressive amplitude and peak frequency distribution at $30 \%, 60 \%$, and $90 \%$ of the failure load. (a) amplitude distribution; (b) peak frequency distribution.

\subsection{Cluster Analysis of AE Signals}

$\mathrm{K}$-means is an effective pattern recognition technique which distinguishes superimposed $\mathrm{AE}$ signals and is performed using MATLAB. Before the multi-parameter analysis of the AE signals, it is necessary to select the representative AE signals and confirm the optimal cluster number. To ensure the efficiency of the algorithm's execution, according to the reference [32], five AE parameters such as AE rise time, duration, energy, peak amplitude, and frequency are selected to carry out the clustering task [46]. In addition, the optimal number of clusters is determined by the silhouette value which is defined as:

$$
s=\frac{1}{n} \sum_{i=1}^{n} \frac{[\min (a(x, k)-b(x))]}{\max [b(x), \min (a(x, k))]}
$$

Here, in cluster $k, a(x, k)$ and $b(x)$ represent the average distance of inter-class and intra-class, respectively. The range of the silhouette value is from -1 to 1 .

The number of clusters evaluated by the silhouette index is shown in Figure 10. It can be found that the maximum silhouette value is 0.95 at $k=3$ and this results in a better clustering quality. Therefore, indicating that $k=3$ is optimal for cluster analysis. 


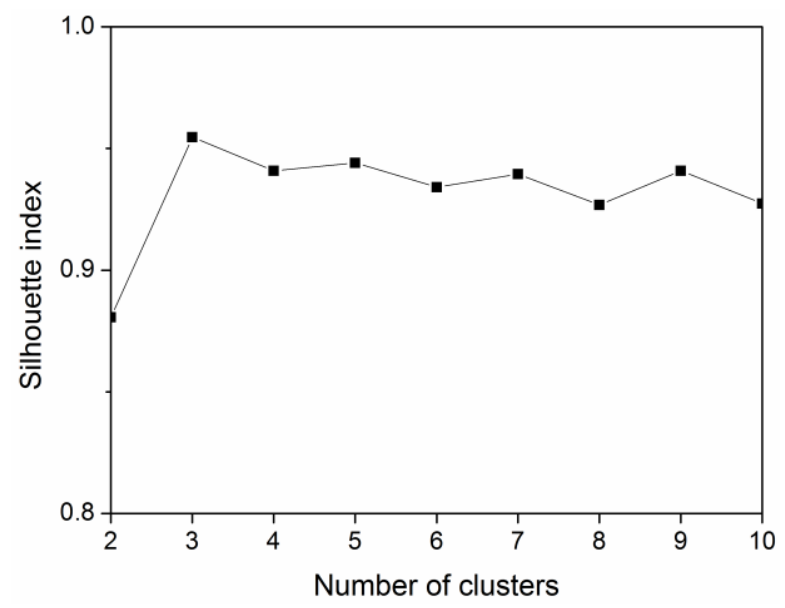

Figure 10. Silhouette value as the function of the number of clustering class, $k$.

The cluster results for each class are shown in Figure 11 and three clusters, CL-1, CL-2, and CL-3, are obtained. The irregular pentagons are interpreted for the average values of five AE parameters and linked by the red line. Obviously, there are the differences in the statistical dispersion for clusters, which means the unsupervised pattern recognition algorithm leading to a better separation of the $\mathrm{AE}$ data. The results indicate that the K-means algorithm is suitable for the purpose of classifying the AE data and distinguishing between the different damage modes.
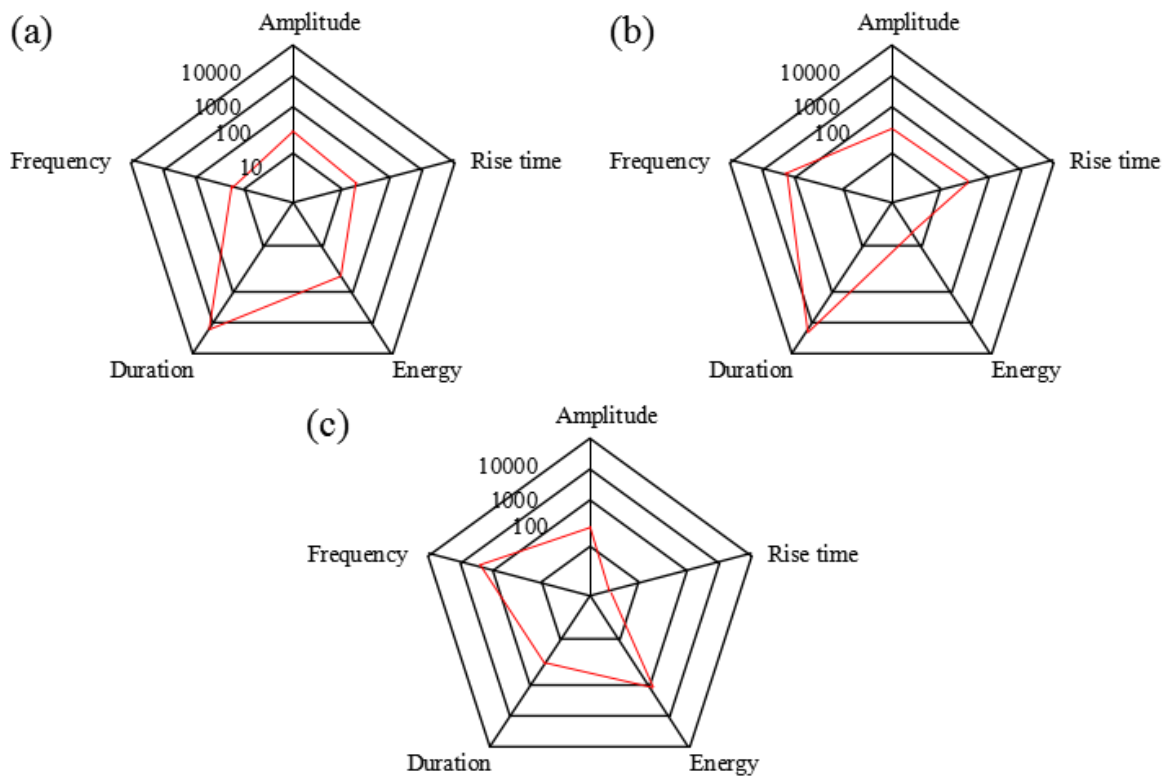

Figure 11. Average properties of three clusters with regard to the five AE parameters. (a) Class CL-1, (b) CL-2, and (c) CL-3.

More importantly, it is necessary to establish the relationship between clusters and damage modes. The peak frequency can accurately describe information on fault-specific AE signals and characterize the change in damage mode associated with progressive failure. Therefore, according to the fundamental assumptions, it is possible to associate specific failure mechanisms with three clusters.

The mechanism-based analysis of AE signals to establish the relationship between clusters and damage modes is shown in Figure 12. The clusters referred to as CL-1, CL-2, and CL-3 are clearly separated by peak frequency as shown in Figure 12a. It is found that class CL-1 and CL-2 appear simultaneously as the applied load under $50 \%$ of the failure load. In addition, the SF trend is shown in Figure $12 \mathrm{~b}$ and indicates that the combination of $S_{1}$ and $S_{2}$ corresponds to the loss of the strain energy 
storing capability. According to the literature [38], these typical AE signals are associated with matrix cracking and fiber/matrix debonding. The possibility to discriminate class CL-1 and CL-2 depends on the different process of visco-elastic relaxation for matrix cracking and the delamination of composites. The relation between peak frequencies $f$, the relaxation times $t$, elastic module $E$, and densities $\rho$ can be defined as:

$$
f \sim \frac{1}{t} \sim \sqrt{\frac{E}{\rho}}
$$

Therefore, the matrix cracking occurs in a lower frequency band than the fiber/matrix debonding. Class CL-1 corresponds to the dominant frequency from 0 to $100 \mathrm{kHz}$ which is lower than that of CL-2 with a frequency range from 150 to $300 \mathrm{kHz}$. Additionally, class CL-1 and CL-2 are associated with matrix cracking and fiber/matrix debonding, respectively. However, the matrix cracking corresponding to the frequency range in this paper is higher than that reported in [46]. It is possible that CL-1 corresponds to matrix cracking and is accompanied by delamination. Although delamination does not occur in tensile loading [47], the matrix cracks can accelerate interfacial failure in the composite material which can lead to delamination in the composites. After that, it is noted that the compositions of $\mathrm{S}_{3}$ and BU suggest that the composite specimen restores, in part, the ability to store strain energy. A reasonable explanation for this phenomenon may be attributed to the realignment of fibers at a macroscopic and microcosmic scale. In the case of damage, the strain energy storing capability exceeds the amount of energy that is released and the sentry function is characterized by an increasing function. However, due to the fact that the damage in the material is growing, the slope of this function progressively decreases. The last class, CL-3, appears with a higher peak frequency from 350 to $600 \mathrm{kHz}$ which is usually attributed to fiber breakage, accompanied drop in the SF curve.

(a)

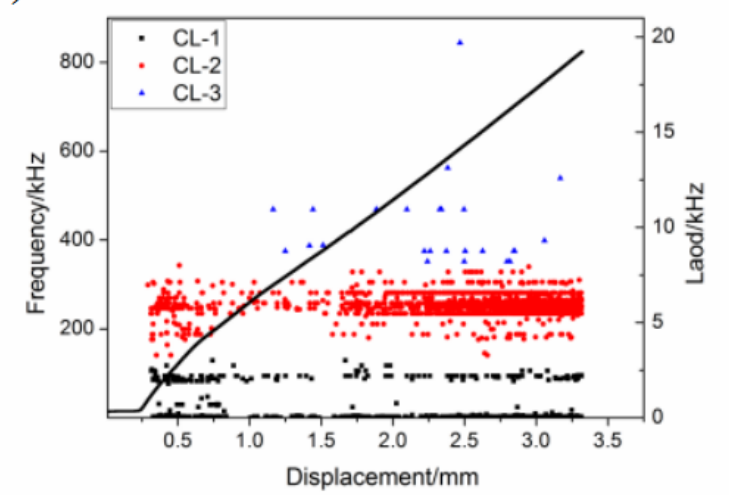

(b)

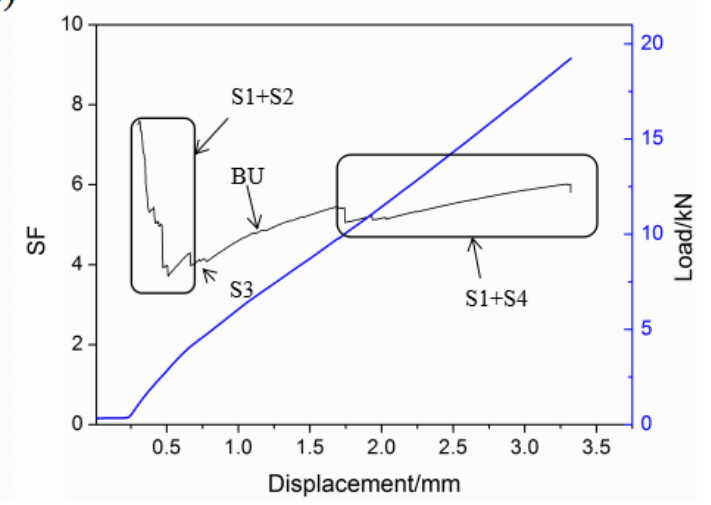

Figure 12. The mechanism-based analysis of AE signals. (a) The distribution of frequency regarding the three clusters and (b) the SF diagram associated with the applied tensile load.

All the failure mechanisms corresponding to the frequency range are summarized in Figure 13. The distribution of the three frequency clusters can well reflect the damage condition of the composites. In addition, combined with Figure 12a, AE signals are mainly concentrated in the range of 150-300 kHz; therefore, the fiber/matrix debonding corresponds to this frequency band and plays a leading role in the failure process of composite specimens. 


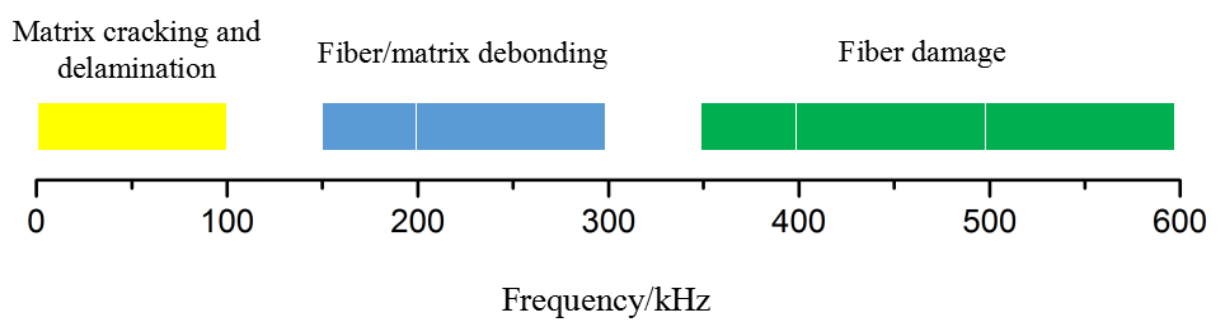

Figure 13. Summary of frequency range for damage mechanisms.

When the energy storing capability decreases, the material damage is increased. At the same time, the tendency of the material to release the internal energy will decrease as well. Thus, when the material damage increases, the ratio between the energy storing capability and the cumulated released energy $\left(E_{s} / E_{a}\right)$ that form the sentry function will decrease. The sentry function can be used to describe the history of the material damage. In particular, the integral of the sentry function is related to the material damage and can be used to predict the residual strength of the composite laminate after an accident and identify the damage evolution process.

\section{Conclusions}

In summary, damage evolution and failure behavior of carbon fiber woven composites were monitored in real time by $\mathrm{AE}$ technology during the tensile tests. AE signals were accurate selected based on AE parameters such as count, energy, peak amplitude, and frequency. Moreover, a complementary method which combined multi-parameters analysis with SF is used to establish the relationship between peak frequency and failure mechanisms in composites. Some important conclusions are summarized as follows:

(1) Under tensile tests, the occurrence of some damage induces AE activity including an increase in accumulative AE energy and count. Specifically, the onset of critical damage is manifested as a high release rate of AE energy and counts.

(2) Compared with the peak amplitude, the progressive frequency distribution shows noticeable variety with the applied load and exhibits a better classification feature for implementing mechanism-based analysis. In addition, at $90 \%$ of the failure load, the AE signals are mainly concentrated in the range of 200 to $300 \mathrm{kHz}$, indicating that fiber/matrix debonding plays a leading role in the later activity of fracture.

(3) By comparison of the cluster results based on a K-means algorithm with the SF curve in AE energy, the relationship between mechanical damage and $\mathrm{AE}$ characteristic parameters was established. Matrix cracking and delamination correspond to low levels of frequency from 0 to $100 \mathrm{kHz}$; the intermediate frequency range from 150 to $300 \mathrm{kHz}$ is associated with fiber/matrix debonding; the higher peak frequency from 350 to $600 \mathrm{kHz}$ was attributed to fiber damage. In addition, the progression of damage motivates the drop in the SF curve. The ability of the composite material to store mechanical energy as shown by the SF curve is a good reflection of the degree and the evolution of damage.

Author Contributions: Conceptualization, W.Z.; Methodology, W.Z., P.-f.Z. and Y.-n.Z.; Software, Y.-n.Z.; Validation, W.Z., P.-f.Z. and Y.-n.Z.; Formal Analysis, P.-f.Z.; Investigation, W.Z., P.-f.Z. and Y.-n.Z.; Resources, W.Z. and Y.-n.Z.; Data Curation, W.Z. and Y.-n.Z.; Writing-Original Draft Preparation, W.Z., P.-f.Z. and Y.-n.Z.; Writing-Review \& Editing, W.Z., P.-f.Z. and Y.-n.Z.

Funding: This research was funded by [the National Natural Science Foundation of China] grant number [11502064], [the Natural Science Foundation of Hebei Province] grant number [E2016201019] and [the Key Projects of Hebei Education Department] grant number [ZD2016097].

Acknowledgments: The authors gratefully acknowledge the financial support of the National Natural Science Foundation of China (grant no. 11502064), and the Natural Science Foundation of Hebei Province (grant no. E2016201019), and the Key Projects of Hebei Education Department (grant no. ZD2016097). 
Conflicts of Interest: The authors declare no conflict of interest.

\section{References}

1. Vautard, F.; Dentzer, J.; Nardin, M.; Schultz, J.; Defoort, B. Influence of surface defects on the tensile strength of carbon fibers. Appl. Surf. Sci. 2014, 332, 185-193. [CrossRef]

2. Penev, E.S.; Artyukhov, V.I.; Yakobson, B.I. Basic structural units in carbon fibers: Atomistic models and tensile behavior. Carbon 2015, 85, 72-78. [CrossRef]

3. Harper, L.T.; Turner, T.A.; Martin, J.R.B.; Warrior, N.A. Fiber alignment in directed carbon fiber preforms-mechanical property prediction. J. Compos. Mater. 2010, 44, 931-951. [CrossRef]

4. Srikanth, L.; Rao, R. Concurrent studies on braided and filament wound carbon fiber composites-A comparative appraisal. J. Reinf. Plast. Compos. 2011, 30, 1359-1365. [CrossRef]

5. Fernandes, H.; Ibarra-Castanedo, C.; Zhang, H.; Maldague, X. Thermographic non-destructive evaluation of carbon fiber-reinforced polymer plates after tensile testing. J. Nondestruct. Eval. 2015, 34, 1-10. [CrossRef]

6. Shinyama, Y.; Yamaji, T.; Hatsukade, Y.; Takai, Y.; Aly-Hassan, M.S.; Nakai, A.; Hamada, H.; Tanaka, S. Nondestructive evaluation of braided carbon fiber composites with artificial defect using HTS-SQUID gradiometer. Phys. C Supercond. Appl. 2011, 471, 1242-1245. [CrossRef]

7. Montesano, J.; Bougherara, H.; Fawaz, Z. Application of infrared thermography for the characterization of damage in braided carbon fiber reinforced polymer matrix composites. Compos. Part B 2014, 60, 137-143. [CrossRef]

8. Baker, C.; Morscher, G.N.; Pujar, V.V.; Lemanski, J.R. Transverse cracking in carbon fiber reinforced polymer composites: Modal acoustic emission and peak frequency analysis. Compos. Sci. Technol. 2015, 116, $26-32$. [CrossRef]

9. Vanniamparambil, P.A.; Carmi, R.; Khan, F.; Cuadra, J.; Bartoli, I.; Kontsos, A. An active-passive acoustics approach for bond-line condition monitoring in aerospace skin stiffener panels. Aerosp. Sci. Technol. 2015, 43, 289-300. [CrossRef]

10. Fazzino, P.D.; Reifsnider, K.L.; Majumdar, P. Impedance spectroscopy for progressive damage analysis in woven composites. Compos. Sci. Technol. 2009, 69, 2008-2014. [CrossRef]

11. Cheng, J.; Qiu, J.H.; Xu, X.J.; Ji, H.; Takagi, T.; Uchimoto, T. Research advances in eddy current testing for maintenance of carbon fiber reinforced plastic composites. Int. J. Appl. Electromagn. Mech. 2016, 51, 261-284. [CrossRef]

12. Stephen, B.C.; Philip, M.K. Experimental results of fatigue testing for calibration and validation of composite progressive damage analysis methods. J. Compos. Mater. 2017, 51, 2083-2100.

13. Hamstad, M.A. Frequencies and amplitudes of AE signals in a plate as a function of source rise time. In Proceedings of the 29th European Conference on Acoustic Emission Testing, Vienna, Austria, 8-10 September 2010.

14. Zelenyak, A.M.; Hamstad, M.A.; Sause, M.G. Modeling of acoustic emission signal propagation in waveguides. Sensors 2015, 15, 11805-11822. [CrossRef] [PubMed]

15. Faisal Haider, M.; Giurgiutiu, V. Theoretical and numerical analysis of acoustic emission guided waves released during crack propagation. J. Intell. Mater. Syst. Struct. 2018. [CrossRef]

16. Haider, M.F.; Giurgiutiu, V. Analysis of axis symmetric circular crested elastic wave generated during crack propagation in a plate: A Helmholtz potential technique. Int. J. Solids Struct. 2018, 134, 130-150. [CrossRef]

17. Wisner, B.; Kontsos, A. Investigation of particle fracture during fatigue of aluminum 2024. Int. J. Fatigue 2018, 111, 33-43. [CrossRef]

18. Zhou, W.; Lv, Z.H.; Li, Z.Y.; Song, X. Acoustic emission response and micro-deformation behavior for compressive buckling failure of multi-delaminated composites. J. Strain Anal. Eng. Des. 2016, 51, $397-407$. [CrossRef]

19. Bussiba, A.; Kupiec, M.; Ifergane, S.; Piat, R.; Böhlke, T. Damage evolution and fracture events sequence in various composites by acoustic emission technique. Compos. Sci. Technol. 2008, 68, 1144-1155. [CrossRef]

20. Yoon, S.J.; Chen, D.D.; Han, S.W.; Choi, N.S.; Arakawa, K. AE analysis of delamination crack propagation in carbon fiber-reinforced polymer materials. J. Mech. Sci. Technol. 2015, 29, 17-21. [CrossRef]

21. Silversides, I.; Maslouhi, A.; LaPlante, G. Acoustic emission monitoring of interlaminar delamination onset in carbon fibre composites. Struct. Health Monit. 2013, 12, 126-140. [CrossRef] 
22. Karahan, M. The effect of fibre volume fraction on damage initiation and propagation of woven carbon-epoxy multi-layer composites. Text. Res. J. 2012, 82, 45-61. [CrossRef]

23. Liu, P.F.; Chu, J.K.; Liu, Y.L.; Zheng, J.Y. A study on the failure mechanisms of carbon fiber/epoxy composite laminates using acoustic emission. Mater. Des. 2012, 37, 228-235. [CrossRef]

24. Crivelli, D.; Guagliano, M.; Eaton, M.; Pearson, M.; Al-Jumaili, S.; Holford, K.; Pullin, R. Localisation and identification of fatigue matrix cracking and delamination in a carbon fibre panel by acoustic emission. Compos. Part B 2015, 74, 1-12. [CrossRef]

25. McCrory, J.P.; Al-Jumaili, S.K.; Crivelli, D.; Pearson, M.R.; Eaton, M.J.; Featherston, C.A.; Guagliano, M.; Holford, K.M.; Pullin, R. Damage classification in carbon fibre composites using acoustic emission: A comparison of three techniques. Compos. Part B Eng. 2015, 68, 424-430. [CrossRef]

26. Woo, S.C.; Kim, T.W. High strain-rate failure in carbon/Kevlar hybrid woven composites via a novel SHPB-AE coupled test. Compos. Part B Eng. 2016, 97, 317-328. [CrossRef]

27. Munoz, V.; Vales, B.; Perrin, M.; Pastor, M.L.; Welemane, H.; Cantarel, A.; Karama, M. Damage detection in CFRP by coupling acoustic emission and infrared thermography. Compos. Part B Eng. 2016, 85, 68-75. [CrossRef]

28. Ryu, Y.R.; Kwon, O.H. Application of AE for Fracture Behavior Evaluation of Carbon-fiber/SiC Reinforced Plastic Composites. Compos. Res. 2017, 30, 267-272.

29. Li, L.B. Micromechanical Modeling for Tensile Behaviour of Carbon Fiber-Reinforced Ceramic-Matrix Composites. Appl. Compos. Mater. 2015, 22, 773-790.

30. Li, L.; Lomov, S.V.; Xiong, Y.; Carvelli, V. Cluster analysis of acoustic emission signals for 2D and 3D woven glass/epoxy composites. Compos. Struct. 2014, 116, 286-299. [CrossRef]

31. Monti, A.; El Mahi, A.; Jendli, Z.; Guillaumat, L. Mechanical behaviour and damage mechanisms analysis of a flax-fibre reinforced composite by acoustic emission. Compos. Part A Appl. Sci. Manuf. 2016, 90, 100-110. [CrossRef]

32. Zhou, W.; Zhao, W.Z.; Zhang, Y.N.; Ding, Z.J. Cluster analysis of acoustic emission signals and deformation measurement for delaminated glass fiber epoxy composites. Compos. Struct. 2018, 195, 349-358. [CrossRef]

33. Davijani, A.A.B.; Hajikhani, M.; Ahmadi, M. Acoustic Emission based on sentry function to monitor the initiation of delamination in composite materials. Mater. Des. 2011, 32, 3059-3065. [CrossRef]

34. Minak, G.; Morelli, P.; Zucchelli, A. Fatigue residual strength of circular laminate graphite-epoxy composite plates damaged by transverse load. Compos. Sci. Technol. 2009, 69, 1358-1363. [CrossRef]

35. Minak, G.; Zucchelli, A. Damage Evaluation and Residual Strength Prediction of CFRP Laminates by Means of Acoustic Emission Techniques; Nova Science Publishers: New York, NY, USA, 2008; pp. 167-209.

36. Han, Z.; Luo, H.; Cao, J.; Wang, H. Acoustic emission during fatigue crack propagation in a micro-alloyed steel and welds. Mater. Sci. Eng. A 2011, 528, 7751-7756. [CrossRef]

37. Li, L.; Zhang, Z.; Shen, G. Influence of grain size on fatigue crack propagation and acoustic emission features in commercial-purity zirconium. Mater. Sci. Eng. A 2015, 636, 35-42. [CrossRef]

38. Rabiei, M.; Modarres, M. Quantitative methods for structural health management using in situ acoustic emission monitoring. Int. J. Fatigue 2013, 49, 81-89. [CrossRef]

39. Maillet, E.; Morscher, G.N. Waveform-based selection of acoustic emission events generated by damage in composite materials. Mech. Syst. Signal Process. 2015, 52-53, 217-227. [CrossRef]

40. Babu, M.R.; Prakash, T.V.B. Characterisation of Fiber Failure Mode in T-700 Carbon Fiber Reinforced Epoxy Composites by Acoustic Emission Testing. Russ. J. Nondestruct. Test. 2014, 50, 45-57. [CrossRef]

41. Chai, M.; Zhang, J.; Zhang, Z.; Duan, Q.; Cheng, G. Acoustic emission studies for characterization of fatigue crack growth in 316LN stainless steel and welds. Appl. Acoust. 2017, 126, 101-113. [CrossRef]

42. Yu, J.; Ziehl, P.; Zarate, B.; Caicedo, J. Prediction of fatigue crack growth in steel bridge components using acoustic emission. J. Constr. Steel Res. 2011, 67, 1254-1260. [CrossRef]

43. Kostopoulos, V.; Loutas, T.H.; Kontsos, A.; Sotiriadis, G.; Pappas, Y.Z. On the identification of the failure mechanisms in oxide/oxide composites using acoustic emission. NDT E Int. 2003, 36, 571-580. [CrossRef]

44. Ullah, H.; Harland, A.R.; Silberschmidt, V.V. Characterisation of mechanical behaviour and damage analysis of 2D woven composites under bending. Compos. Part B 2015, 75, 156-166. [CrossRef]

45. Hatta, H.; Goto, K.; Ikegaki, S. Tensile strength and fiber/matrix interfacial properties of 2D- and 3D-carbon/carbon composites. J. Eur. Ceram. Soc. 2005, 25, 535-542. [CrossRef] 
46. Gutkin, R.; Green, C.J.; Vangrattanachai, S.; Pinho, S.T.; Robinson, P.; Curtis, P.T. On acoustic emission for failure investigation in CFRP: Pattern recognition and peak frequency analyses. Mech. Syst. Signal Process. 2011, 25, 1393-1407. [CrossRef]

47. Lomov, S.V.; Karahan, M.; Bogdanovich, A.E.; Verpoest, I. Monitoring of acoustic emission damage during tensile loading of 3D woven carbon/epoxy composites. Text. Res. J. 2014, 84, 1373-1384. [CrossRef]

(C) 2018 by the authors. Licensee MDPI, Basel, Switzerland. This article is an open access article distributed under the terms and conditions of the Creative Commons Attribution (CC BY) license (http:/ / creativecommons.org/licenses/by/4.0/). 